\title{
Learning Analytics for Improving Learning Materials us- ing Digital Textbook Logs
}

\author{
Kousuke Mouri, Chengjiu Yin and Noriko Uosaki
}

\begin{abstract}
The purpose of this paper is to find meaningful information for improving learning materials using digital textbook logs. The analysis and visualization methods of this study use frequency analysis and heat-map technologies. Logs for improving learning materials were collected in a digital textbook system. In order to analyze and visualize the collected logs, this paper proposes a system called SILM (System for Improving Learning Materials). Using SILM, instructors or teachers can find the points to be improved in the learning materials that they created. An initial evaluation was conducted to evaluate (1) whether the digital textbook system would be beneficial to the learners in terms of usability and degree of satisfaction and (2) whether a teacher can find the points to be improved in the digital textbooks using SILM. Eight graduate and undergraduate students who are studying at university participated in the evaluation experiment. From the results of the evaluation experiment, it was found that the system contributed to find the points to be improved in the digital textbooks.
\end{abstract}

Keywords: Learning analytics, digital textbook, information visualization.

\section{Introduction}

A digital textbook has been known as an e-textbook, electronic book and e-book. Recently, the digital textbook technologies have been introduced to universities and schools in many countries [1], [2], [3]. The increased availability of the digital textbooks has made in-class and out-of-class learning even more convenient. Japanese Ministry of Education, Culture, Sports, Science and Technology announced that a comprehensive policy that promotes utilizing ICT in education [4]. In the policy, the government addressed to introduce the digital textbooks into all K12 schools by 2020. Many countries' digital textbook policies only focus on introducing the technology of digital textbooks. Here are reasons why digital textbooks are becoming educational standard:

(1) Delivery instantly: Learners can download digital textbooks anytime and anywhere. In addition, they can save the e-books on their own computer. Therefore, they don't have to worry about losing and forgetting textbooks somewhere. 
(2) Easily portable: Learners don't have to bring many textbooks to their classroom. They can access their textbooks via internet.

(3) Interactive multimedia: It can be responded to the learners' actions by presenting contents such as texts, moving images, animations, videos, audios, and video games in the digital textbooks.

(4) Easy search: This function makes finding any keywords on the digital textbooks quickly. This helps learners to take clear notes in the digital textbooks.

(5) Highlighting: This function enables learners to highlight important keywords such as they want to remember or they do not understand. Also, it is possible to study later.

In digital textbook studies, majority of researchers reported that smart learning environments where digital textbook technologies are introduced are expected to enhance the learning efficacy and quality of education [1], [2]. However, little attention has been paid to analyzing and visualizing the collected digital textbook logs in order to improve learning materials. $\mathrm{Gu}$ et al. [5] reported the importance regarding the design of digital textbooks and suggested that well-designed digital textbooks positively enhance learning. Therefore, it is necessary to find the points to be improved in the digital textbooks. This study developed a system called SILM (System for Improving Learning Materials). SILM can find the points to be improved in the digital textbooks by analyzing and visualizing learning logs accumulated in the system. This study evaluated and discussed the following two points: 1) whether the digital textbook system would be beneficial to the learners in terms of usability and the degree of satisfaction, and 2) whether a teacher can find the points to be improved in the digital textbooks using SILM.

\section{Literature Review}

\subsection{Learning analytics}

Learning Analytics (LA) is measurement, collection, analysis and reporting of data about learners and their contexts, for the purpose of understanding and optimizing their learning [6]. The biggest benefits can be pursued through the discovery and understanding of the data's hidden information. Based on LA, many educational institutions have been increasingly analyzing available datasets in order to enhance students' learning. It is necessary and significant to consider how the logs collected by a digital textbook system with LMS (Learning Management System) can be used to improve learning and teaching.

For example, the dashboard is one of visualization ways by which students can easily understand their learning progress and results [7], [8]. According to [9], they reported that information visualization such as network graph based on graph theory, 3D representation and heat-map is often more effective than plain text or data. Similarly, some researchers focus on predicting students' final grades by analyzing learning logs and the results of the reports and tests of students who took same course in the previous semester [10], [11], [12]. We believe that visualization for LA is a useful way in order to understand their learning progresses, results and the points to be improved in the learning materials. Previous researches indicated that LA can improve the digital textbooks. For example, Mouri \& Yin ( 2017) collected digital textbooks' logs to discovery some patterns to improve the digital textbooks, they found that if many learners frequently clicked the zoom button in a page, figures and letters in the page might be relatively too small. This finding 
can be used to improve the design of the digital textbooks [13]. As another example, by analyzing digital textbooks' logs, Yin et al. (2017) found that students often changed the important keywords when they were reading the textbook, as the students always take action like "After adding highlight on a text, the students deleted the another highlight"[14].

\section{Learning Analytics Model for Improving Learning Materials}

Firstly, it is necessary to consider how systems collect and clean data. Secondly, it is necessary to consider analysis ways for improving learning materials using the collected and cleaned data. Based on the analysis results, it is expected that teachers can improve students' learning materials based on their own judgement. Based on a related research with these considerations in mind [15], this paper proposes the learning analytics model for improving learning materials as shown in Figure 1.

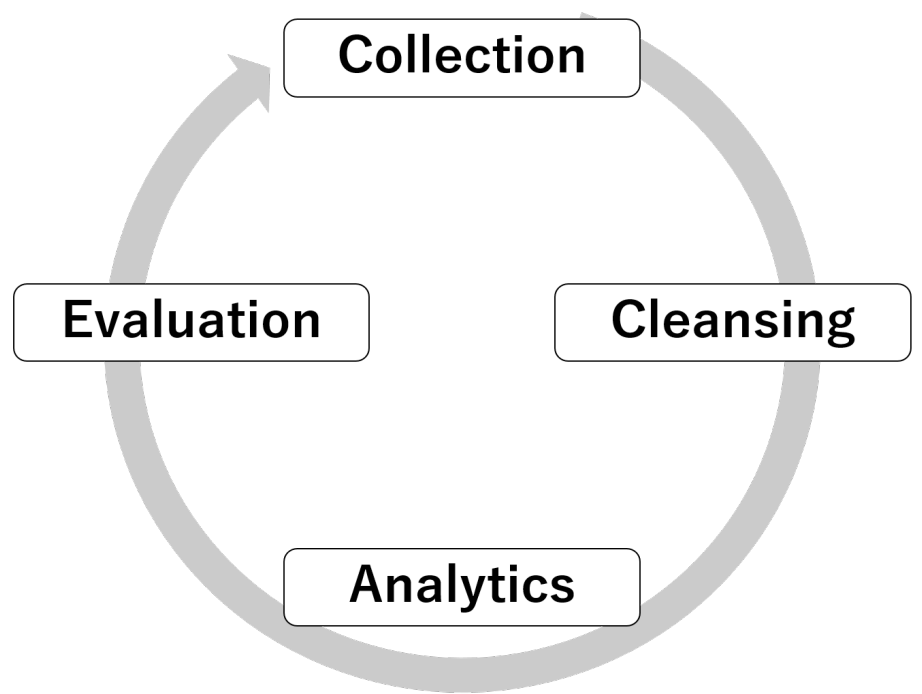

Figure 1: Learning analytics model for e-book logs

- Collection: Generally, at the data collection stage, data will be collected from the digital textbook system. By using the system, operation logs of each student can be collected.

- Cleansing: It is unavoidable to have repetitive or invalid data among those obtained from data collection, therefore the sorting and cleaning process is needed. According to [16], the data cleansing is especially required when integrating heterogeneous data. Most of researchers in the data cleansing described [17], [18] that it is necessary to do this process if analyzing and visualizing big data because duplicated or missing information will product incorrect or misleading statistics ("garbage in, garbage out"). By realizing this process, the speed of visualizing and analyzing educational big data collected by systems can be improved.

- Analytics: Analytics is carried out based on perspective of LA. The objectives of this analytics is to detect or mine the learning materials that should be improved using analysis and visualization technologies. 
- Evaluation: Our developed system, SILM is evaluated by the instructors or teachers whether they can find the points to be improved in the learning materials by them.

All the above processes can be supported by SILM. By realizing the process, teachers and instructor designers can judge whether the teaching slides should be revised or not. In addition, they can discuss and share the information each other.

\section{System Design}

\subsection{Digital Book System}

Our developed digital textbook system consists of two main components:

(1) Digital textbook uploader: Teachers usually used paper-based textbooks for their courses, which are distributed by various publishing companies. Thus, it is difficult to make these textbooks available on the digital textbook system due to copyright issues. This study currently uses their original lecture slides (PowerPoint or PDF) that are created by the teachers. Our developed digital textbook system converts the lecture slides into an E-PUB (Electronic PUBlication) files. Figure 2(left) shows the uploader interface. Teaches can upload their slides before class using the interface. Figure 2(right) shows the list of slides uploaded by the teachers.

(2) Digital textbook reader: Students can read the slides on the web browser anytime and anywhere. Figure 3 shows the digital textbook reader interface. By using the interface, students can use some functions such as next page, previous page, zoom-in, zoom-out, bookmark, highlight and memo. For example, when a student clicks the memo button on the interface, the student can save a description about his/her target word. In addition, the student can find his/her target word by using search function. Their operation logs can be collected into database.
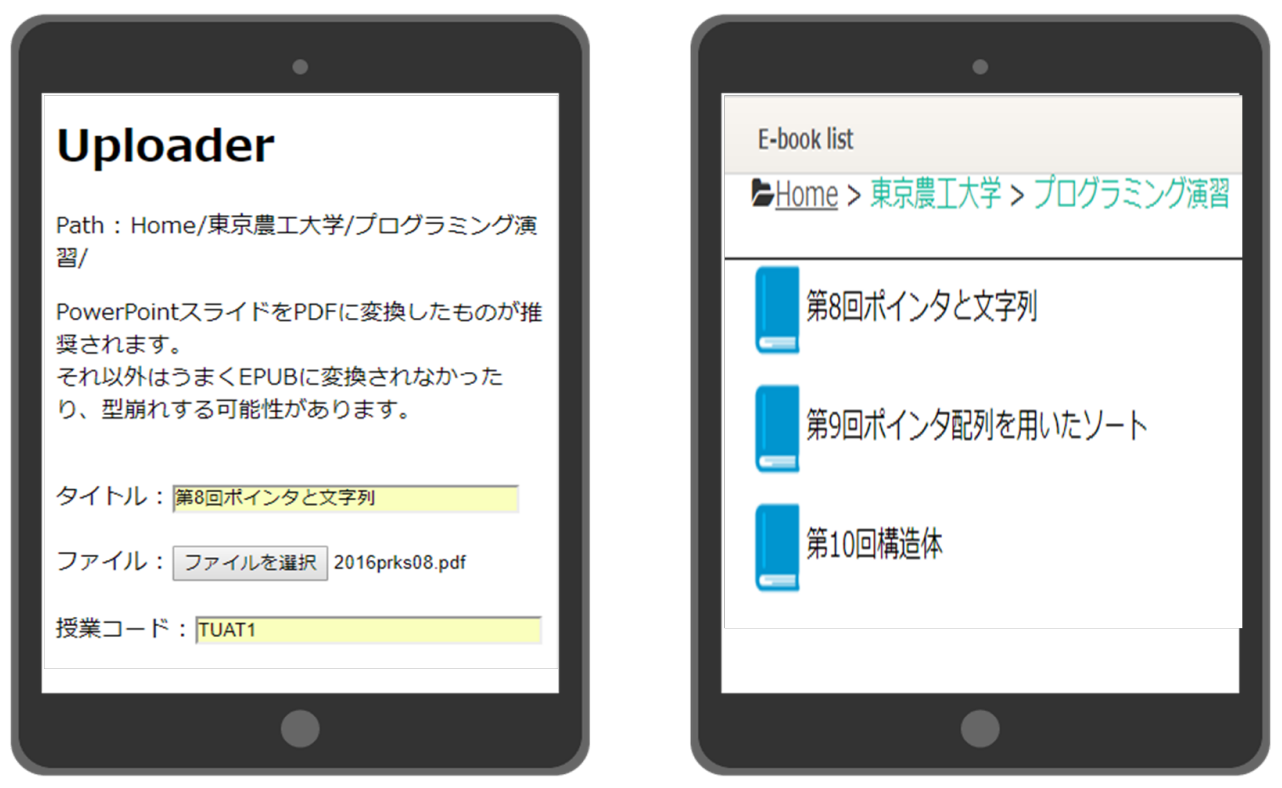

Figure 2. Digital textbooks uploader interface (left) and list of uploaded textbooks (right) 


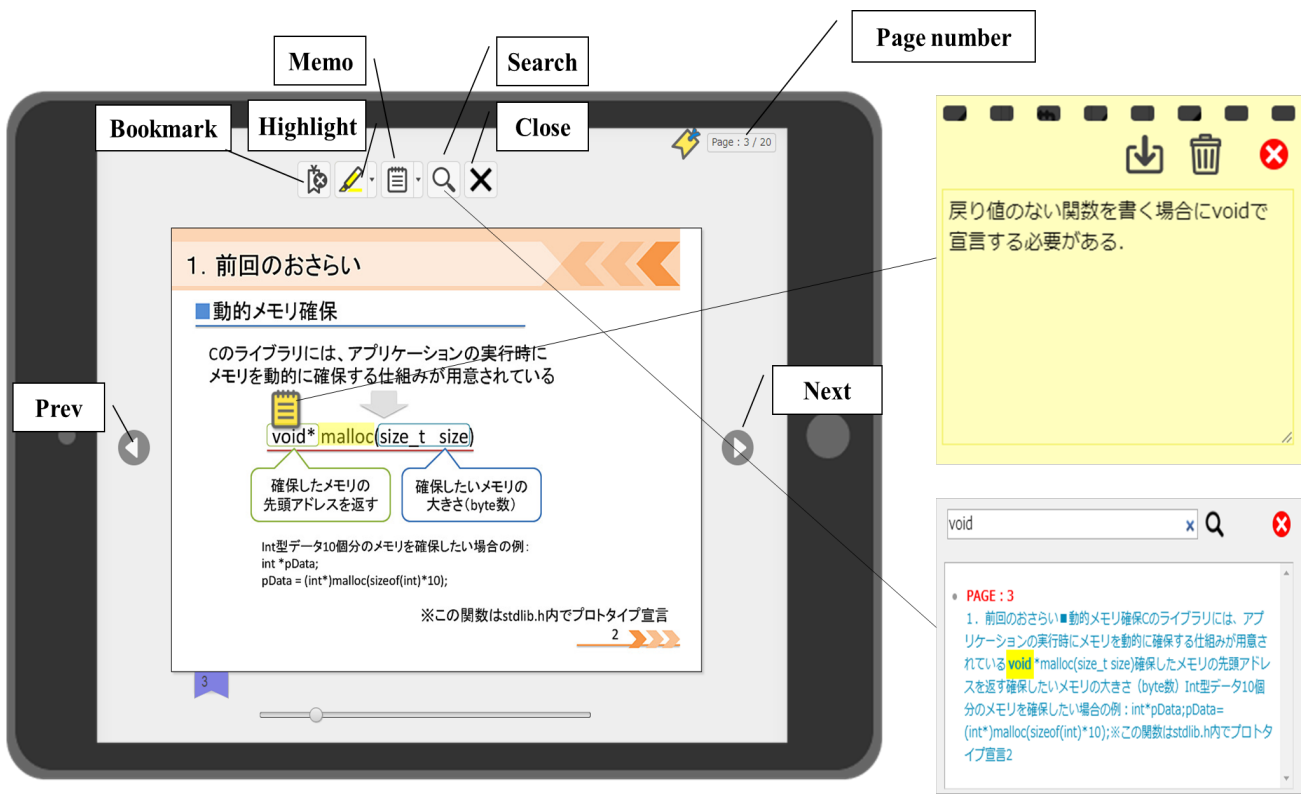

Figure 3. Digital textbooks reader interface

\subsection{SILM: System for Improving Learning Materials}

SILM is a web application and it is programmed using PHP and Java [15]. Figure 4 shows the visualization interface of the heat-map of SILM.

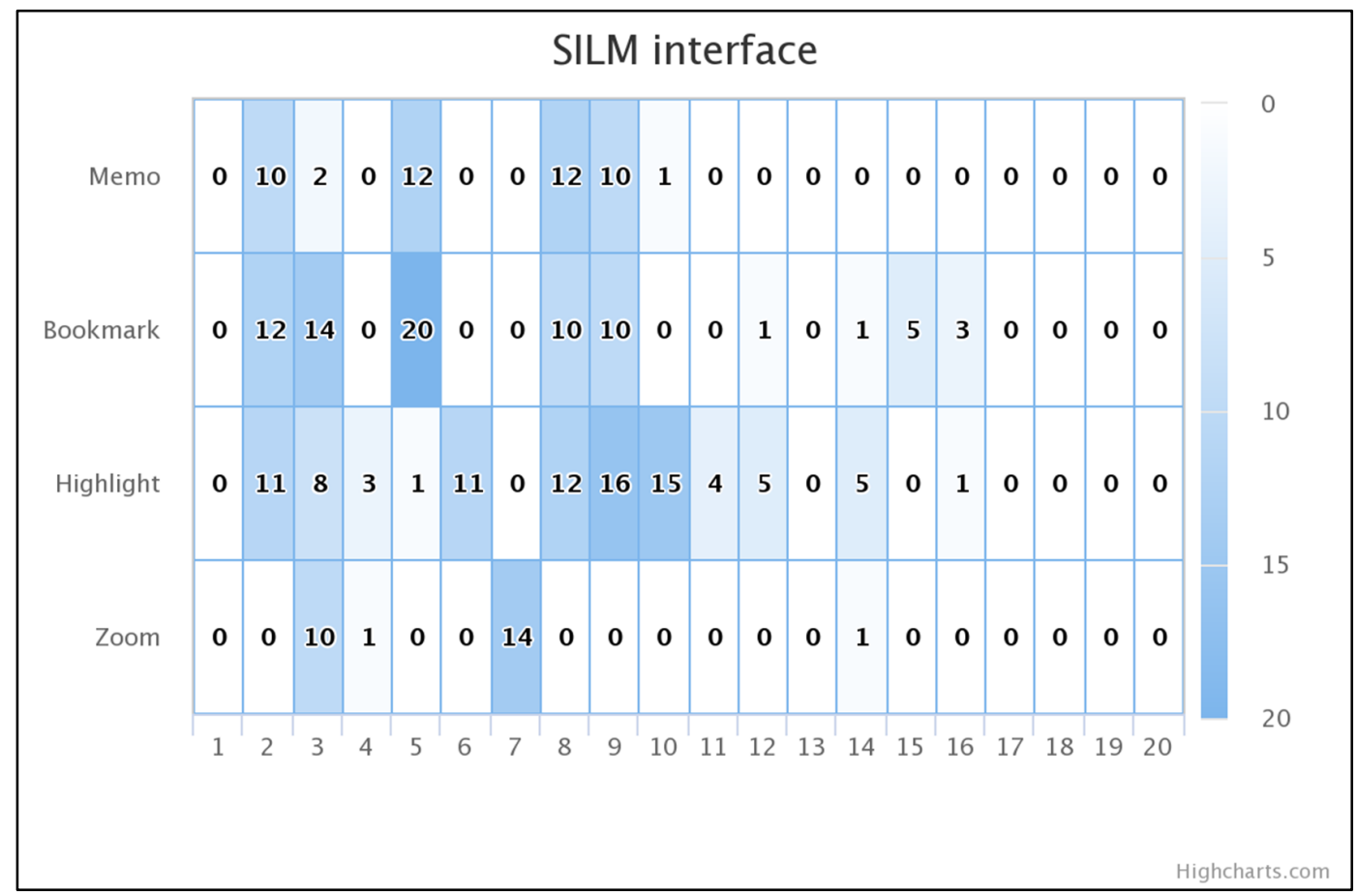

Figure 4. SILM interface 
The rows show the page number of the slides. The columns show memo, bookmark, highlight and zoom function. The color scale is decided from white (low) to blue (high). The color of each cell represents the number of each operation with page number.

Instructors or teachers can check the visualization results and then they can find the pages to be improved in the digital textbooks. In this case, teachers can find the page number 3 and 7 of the digital textbook that should be improved because the learners frequently used the zoom function. Therefore, there is a possibility that the letters and figures were too small for them to read. The teachers can check whether students actively used memo, bookmark and highlight functions. If students did not use them, there is a possibility that they might be poor motivation. It is necessary to design interactive digital textbooks that students can interact with functions such as audios, videos, and so on.

\section{Evaluation}

\subsection{Participants and purpose}

Eight graduated students at the Tokyo University of Agriculture and Technology participated in the evaluation experiments. The learning content is $\mathrm{C}$ programming language. The evaluation experiment was designed to evaluate the following two points:

(1) Whether the developed digital textbook system would be beneficial in terms of usability and the degree of satisfaction.

(2) Whether the teacher can find the points to be improved in the digital textbooks from analysis results.

\subsection{Method}

Before the evaluation experiment, a teacher uploaded two slides titled "Pointer and Characters String" and "Structure" regarding C programming language and explained how to use the digital textbook system. The participants were instructed to use their own note-PC or desktop-PC to read the uploaded slides in informal settings anytime and anywhere. They read the slides for one and a half hours to study $\mathrm{C}$ programming language. After the evaluation experiment, the participants were asked to complete five point-scale questionnaires to evaluate (1) Whether the developed digital textbook system would be beneficial in terms of their usability and the degree of satisfaction. Furthermore, in order to evaluate the effectiveness of our system, the teacher was asked to examine whether he could find the parts to be improved in the digital textbooks from the results of the analysis by SILM.

\subsection{Result and discussion}

Table 1 shows the results of the five-point-scale questionnaire. 
Table 1. The results of the five-point-scale questionnaire

\begin{tabular}{|l|l|l|}
\hline Question & Mean & SD \\
\hline Q1. Was the digital textbook system easy to use? & 3.5 & 1.3 \\
\hline Q2. Was it fun for you to use the digital textbook system? & 3.5 & 0.89 \\
\hline $\begin{array}{l}\text { Q3. Were the bookmark, highlight and memo functions helpful } \\
\text { for your learning? }\end{array}$ & 3.14 & 1.14 \\
\hline $\begin{array}{l}\text { Q4. Please rate how much you liked or disliked the whole sys- } \\
\text { tem. }\end{array}$ & 3.75 & 1 \\
\hline
\end{tabular}

Q1 asks that the digital textbook system was easy to use. Q2 asks whether the participants felt that it was fun to use the digital textbook system. Their feedback indicated that the digital textbook system was easy to use and fun for learning. Q3 asks whether the participants felt that digital textbook functions such as bookmark and memo were helpful for their learning. Q4 asks of the user acceptance of the whole system. The mean score of Q4 was the highest of all.

Figure 5 shows the results of SILM based on the digital textbook logs after the evaluation experiment.

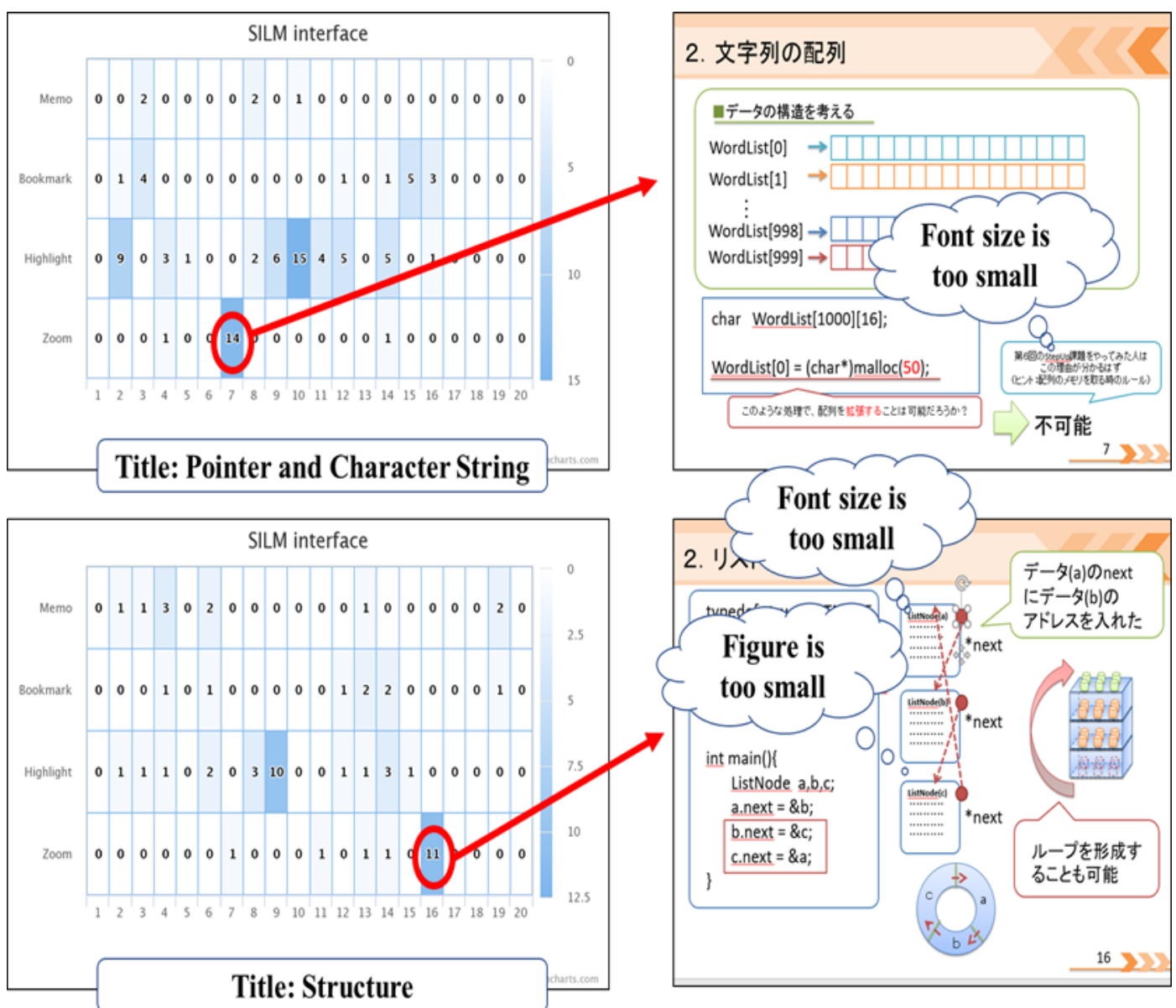

Figure 5. The results of SILM based on digital textbook logs 
From the results, teachers were able to find the page number of each slide where they frequently used the zoom function, as follows: (1) page number 7 of the slide titled "Pointer and Character String" and (2) page number 16 of the slide titled "Structure". Following the above results, teachers checked the page of each slide. They found problems such as "font size is too small" and "figure size is too small". As a result, students frequently highlighted a keyword on the page number 10. This mean that important page should be shared each student. In our future work, we will consider that providing the important page to students in accordance with their reading histories. Moreover, next consideration will be planned to design interactive digital textbooks based on the analysis results.

\section{Conclusion}

This paper described a system called SILM for improving learning materials using digital textbook logs. Logs for improving learning materials were collected in a digital textbook system. A questionnaire with a five-point-scale conducted after the evaluation showed our developed digital textbook system would be beneficial in terms of usability and the degree of satisfaction. In order to find the points to be improved in the learning materials, this study analyzed and visualized digital textbook logs collected during the evaluation experiment. As a result, this study found pages that students frequently used zoom function. By checking the analysis results of SILM, teachers were able to find the pages to be improved. SILM will be evaluated repeatedly, with digital textbooks of not only programming language but also other application domains such as language learning [19] and career support [20]. Furthermore, we will consider smart digital textbook system to more effectively assist students and teachers using graph theory [21], pattern mining [10], [11], real-time analysis [22], [23] technology and Bayesian modeling [24], as proposed by several researchers. In addition, we will consider standard questionnaire like System Usability Scale (SUS) and Technology Acceptance Model (TAM) in order to evaluate precise usability of the digital textbook system.

\section{Acknowledgement}

The part of this research work was supported by the Grant-in-Aid for Scientific Research No.16H03078 and No. 17K12947 from the Ministry of Education, Culture, Sports, Science and Technology (MEXT) in Japan.

\section{References}

[1] H. Fang, P. Liu and R. Huang, "The Research on E-book-oriented Mobile Learning 
System Environment Application and Its tendency", International Conference on Computer Science and Education, 1333- 1338, 2011.

[2] J. A. Shin, "Analysis on the digital textbook's different effectiveness by characteristics of learner", International Journal of Education and Learning, Vol.1, No.2, 23-38, 2012.

[3] M. Kiyota, K. Mouri, N. Uosaki and H. Ogata, "AETEL: Supporting Seamless Learning and Learning Log Recording with e-Book System", Proc. Of the $24^{\text {th }}$ International Conference on Computers in Education 2016 (ICCE 2016), pp. 380-385, 2016.

[4] MEXT, Japanese Ministry of Education, Culture, Sports, Science and Technology, "The Vision for ICT in Education", http://www.mext.go.jp/b_menu/houdou/23/04/_icsFiles/afieldfile/20 12/08/03/1305484_14_1.pdf.

[5] X. Gu, B. Wu, X. Xu. Design, development, and learning in e-Textbooks: what we learned and where we are going. Journal of Computers in Education, 2(1), 25-41, 2015.

[6] B. S., Simon. (2012). Learning Analytics Policy Brief, http://iite.unesco.org/pics/publications/en/files/3214711.pdf

[7] E. Lkhagvasuren, K. Matsuura, K. Mouri and H. Ogata, Learning Log Dashboard: to see your own progress, proc. of the $22^{\text {nd }}$ International Conference on Computers in Education (ICCE 2014), 539-544, 2014.

[8] E. Lkhagvasuren, K. Matsuura, K. Mouri, H. Ogata, "Dashboard for analyzing ubiquitous learning log”, International Journal of Distance Education Technologies, 14(3), pp.1-20.

[9] R. Mazza, Introduction to Information Visualization. Springer-Verlag, London, 2009.

[10] C. Yin, F. Okubo, A. Shimada, M. Oi, S. Hirokawa, M. Yamada, K. Kojima, H. Ogata,” Analyzing the Features of Learning Behaviors of Students using e-Books", International Conference on Computer in Education (ICCE 2015), 617-626, 2015.

[11] C. Yin, F. Okubo, A. Shimada, M. Oi, S. Hirokawa, M. Yamada, K. Kojima and H. Ogata, "Identifying and Analyzing the Learning Behaviors of Students using e - Books", Proc. of the 22nd International Conference on Computers in Education 2015 (ICCE 2015), pp.118-120, 2015.

[12] K. Mouri, C. Yin, F. Okubo, A. Shimada and H. Ogata, "Profiling High-achieving students using E-book-based Logs", the first international workshop on Learning Analytics and Knowledge (LAK 16), pp.1-6, 2016.

[13] K. Mouri, C. Yin, E-book-based learning analytics for improving learning materials. In T. Matsuo et al. (Eds), Proc.of the 6th IIAI International Congress on Advanced Applied Informatics, pp. 493-497, 2017

[14] C. Yin, N. Uosaki, H. C. Chu, G. J. Hwang, J. J. Hwang, I. Hatono, E. Kumamoto, \& Y. Tabata, Learning behavioral pattern analysis based on students' logs in reading digital books. Proc.of the 25th International Conference on Computers in Education, pp. 549557, 2017. 
[15] G. Siemens, Learning analytics: envisioning a research discipline and a domain of practice, the 2nd International Conference on Learning Analytics and Knowledge, pp.4$8,2012$.

[16] E. Rahm and H. H. Do Data cleaning: Problems and current approaches, IEE Data Eng. Bull, Vol.23, No.4, pp.3-13, 2000.

[17] S. Chaudhuri and U. Dayal, An Overview of Data Warehousing and OLAP Technology, International Conference on Management of Data (SIGMOD), Vok1.26, No.1, pp.65-74, 1997 ,

[18] S. Chaudhuri, K. Ganjam, V. Ganti, R. Kapoor, V. Narasaya and T. Vassilakis, Data cleaning in Microsoft SQL Server 2005, ACM SGMOD, pp.918-920, 2005.

[19] H. Ogata, B. Hou, N. Uosaki, K. Mouri and S. Liu, "Ubiquitous learning project using life-logging technology in Japan", Educational Technology \& Society, Vol.17, No.2, pp.85-100, 2014.

[20] N. Uosaki, H. Ogata, K.Mouri and E. Lkhagvasuren, "Career Support for International Students in Japan Using Ubiquitous Learning Log System”, The 15th IEEE International Conference on Advanced Learning Technologies (ICALT2015), pp.78-82, 2015.

[21] K. Mouri and H. Ogata, Ubiquitous Learning Analytics in the Real-world Language Learning, Smart Learning Environments, Vol.2, No.15, 1-18, 2015.

[22] A. Shimada, K. Mouri and H. Ogata, Real-Time Learning analytics of e-Book Operation Logs for On-site Lecture Support, the $17^{\text {th }}$ International Conference on Advanced Learning Technology, pp.274-275, 2017.

[23] K. Mouri, A. Shimada, C. Yin, N. Uosaki, V. Tengchaisri, K. Kaneko, Real-time Analysis of Digital Textbooks: What keywords Make Lecture Difficut?, the $25^{\text {th }}$ International Conference on Computers in Education, in press, 2017.

[24] K. Mouri, F. Okubo, A. Shimada, H. Ogata, Bayesian Network for Predicting Students7 Final Grade Using e-Book Logs in University Education, the $16^{\text {th }}$ International Conference on Advanced Learning Technology, pp.85-89, 2016. 